(RESEARCH ARTICLE)

\title{
Epidemiological and clinical profile of novel coronavirus disease (COVID 19) in a hospital in Metropolitan India
}

\author{
Priti Chowdhary ${ }^{1, *}$, Ritesh Ranjan ${ }^{2}$, Cecil C Khakha ${ }^{1}$, Deepika Govil ${ }^{1}$, Munesh Kasana ${ }^{1}$ and Deepika C \\ Khakha ${ }^{3}$
}

${ }^{1}$ ESI Hospital, Okhla, New Delhi, India.

${ }^{2}$ ABG Hospital, Moti Nagar, New Delhi, India.

${ }^{3}$ College of Nursing, AIIMS, New Delhi, India.

Publication history: Received on 06 October 2020; revised on 19 October 2020; accepted on 22 October 2020

Article DOI: https://doi.org/10.30574/wjarr.2020.8.1.0370

\begin{abstract}
Context: To understand the epidemiological and clinical profile of COVID 19.

Aims: To study the epidemiological and clinical profile of Novel Coronavirus disease with comorbidities and outcome. Settings and Design: In this single centre study, we included patients with suspected and confirmed cases of COVID 19

Methods and Material: We followed the testing criteria for COVID 19 laid down by Ministry of Health and Family Welfare (MoHFW), Government of India. COVID 19 positive patients were divided as mild, moderate and severe and followed till discharge or death. Data was collected through interview of patients and hospital records.

Results: A total of 178 suspected cases of COVID 19 reported to our hospital in this duration. Out of these, confirmed positive cases were 66 in number. Among 66 COVID 19 positive patients 11 were Health Care Workers. The Median age of the patients was 37 years. Most of the confirmed COVID patients were young and middle aged between 15 to 49 years age $(69.69 \%) .66 .66 \%$ were males and $33.33 \%$ were females. Case fatality rate was $4.54 \%$. In our study only $15.15 \%$ had history of contact with COVID 19 positive patients.

Conclusions: Fever is the most common presenting symptom but fever should not be the exclusion criteria. Since there is silent spread of virus in the community among the asymptomatic patients there is need to increase the number of testing. Containment and mitigation strategy like Social distancing should be maintained. Routine screening of Health Care Workers should be done.
\end{abstract}

Keywords: COVID 19; Novel Coronavirus 2019; Lockdown; Global pandemic

\section{Introduction}

The most researched coronaviruses are Infectious Bronchitis Virus (IBV), Mouse Hepatitis Virus (MHV) and Severe Acute Respiratory Syndrome Coronavirus (SARS-CoV). [1] These particles are enveloped, 80- to 220-nm particles containing unsegmented genome of single stranded positive sense RNA (20-30 kb; MW 5-6x 106. These have the largest genomes known [around 30 kilobases (kb)] among RNA viruses.[2] Coronaviruses are host specific and cause respiratory diseases and Gastrointestinal diseases. [3] Recently identified SARS-CoV 2 (Novel Coronavirus 2019) is the causative agent of SARS.[4] WHO reported SARS-CoV2 on 31st December 2019. WHO declared COVID 19 outbreak a global health emergency on 30 January, 2020. WHO declared COVID 19 a global pandemic on March 11, 2020. It is first pandemic since declaring H1N1 influenza a pandemic in 2009.[5]

\footnotetext{
* Corresponding author: Dr Priti Chowdhary

ESI Hospital, Okhla, New Delhi, India.

Copyright (C) 2020 Author(s) retain the copyright of this article. This article is published under the terms of the Creative Commons Attribution Liscense 4.0.
} 
COVID 19 is an ongoing cluster of respiratory tract illness caused by Novel beta Coronavirus, 2019 novel Coronavirus (2019 $\mathrm{n} \mathrm{CoV}$ ). Here we report the epidemiological and clinical profile with radiological features and associated comorbidities of Coronavirus disease in a hospital in metropolitan India.

The Centre for Disease Control and Prevention (CDC) reports that incubation period of disease can range from 2-14 days. COVID 19 patients may have following symptoms:[6]

- Fever or Chills

- Cough

- Shortness of breath or difficulty breathing

- Fatigue

- Myalgia

- A new loss of taste or smell

- Sore throat

- Nausea or Vomiting

- Diarrhoea

According to The World Health Organization (WHO) some other less common symptoms include diarrhoea, headache, a skin rash and discoloration of fingers or toes.[7]

\section{Material and methods}

In this single centre study, we recruited patients with suspected and confirmed cases of COVID 19 who presented in our hospital from 1st April to 12 June 2020.

Case definition for COVID 19 was followed as per Ministry of Health and family Welfare (MOHFW), Government of India. Initially any person who presented with Severe Acute Respiratory Infection (SARI) AND any one of the following i.e.

A history of travel from Wuhan, China in 14 days prior to symptoms onset;

Disease in healthcare worker working in environment of SARI patients;

Unusual or unexpected clinical course, especially sudden deterioration despite appropriate treatment; were to be urgently investigated.

Patient selection criteria for COVID 19 testing was modified by Government of India from time to time. It was modified on June 2, 2020 and accordingly, new strategy for COVID-19 Testing was

All symptomatic (ILI symptoms) individuals with history of international travel in the last 14 days.

All symptomatic (ILI symptoms) contacts of laboratory confirmed cases,

All symptomatic (ILI symptoms) healthcare workers/frontline workers involved in containment and mitigation of COVID 19.

All patients of Severe Acute Respiratory Infection (SARI).

Direct and high-risk contacts (diabetic, hypertension, cancer patient and senior citizen) of a confirmed case to be tested once between day 5 and day 10 of coming into contact with a confirmed case

All symptomatic ILI within hotspots/containment zones.

All hospitalized patients who develop ILI symptoms

All symptomatic ILI among returnees and migrants within 7 days of illness.

(ILI case is defined as one with acute respiratory infection with fever $>380 \mathrm{o}$ AND cough.)

(SARI case is defined as one with acute respiratory infection with fever $>38$ oC AND cough AND require hospitalization.)

All testing in the above categories was done by real time RT-PCR test only. The nasopharyngeal and oropharyngeal swab of these patients were taken and sent in laboratory maintaining cold chain.

COVID 19 SARS CoV-2 real time PCR assay was performed. Kit used for COVID 19 was Real Star SARS CoV manufactured by Altona Diagnostics Germany. 
Viral genome tested in this kit target $\mathrm{E}$ gene (lineage B- $\beta$ CoV specific RNA) and target S gene (SARS CoV- 2 specific RNA). This test is based on reverse transcriptase PCR technology for the qualitative detection and differentiation of lineage $B$ $\beta$ Coronavirus (B $\beta \mathrm{CoV}$ ) and severe acute respiratory syndrome Coronavirus 2 (SARS CoV-2) specific RNA.

According to severity of symptoms patients were categorized as mild, moderate and severe. Mild cases included those with fever and upper respiratory symptoms only. Moderate cases included patients with pneumonia with no signs of severe disease and respiratory rate (RR) $\geq 24 / \mathrm{min}$ and Sp02 $<94 \%$ on room air. Severe patients included those with respiratory distress requiring mechanical ventilation ( non-invasive \& invasive) with $\mathrm{RR} \geq 30 / \mathrm{min}$ and SpO2<90\% on room air.

Mild or asymptomatic cases were admitted in Covid care Centre (CCC). Patients who needed medical attention were kept in Covid Health Centre (CHC) and severely ill patients who needed close monitoring were kept in COVID Dedicated Hospitals.

All patients who reported in our fever clinic and casualty were interviewed and details were noted in a form which was used for collection of data for this study.

Patients were followed for their duration of stay in hospital till desired or undesired outcome. Desired outcome was no symptom for 10 days and undesired outcome was death of patients.

\section{Results and discussion}

Table 1 Median Age and Sex ratio of COVID 19 positive cases

\begin{tabular}{|l|l|}
\hline Characteristics & \\
\hline Median Age & 37 \\
\hline Inter Quartile Range (IQR) & $30-51$ \\
\hline Female sex & $22 / 66(33.33 \%)$ \\
\hline Male sex & $44 / 66(66.66 \%)$ \\
\hline
\end{tabular}

Table 2 Contact history and Travel history of COVID 18 positive cases

\begin{tabular}{|l|l|}
\hline $\begin{array}{l}\text { Had contact history with COVID 19 positive } \\
\text { patients within past 14 days }\end{array}$ & $10 / 66(15.15 \%)$ \\
\hline $\begin{array}{l}\text { No contact history with COVID 19 positive patients } \\
\text { within past 14 days }\end{array}$ & $56 / 66(84.84 \%)$ \\
\hline $\begin{array}{l}\text { Positive travel history to China/ Abroad in last } 14 \\
\text { days }\end{array}$ & $0 / 66(0 \%)$ \\
\hline
\end{tabular}

Table 3 Age distribution of COVID 19 positive cases

\begin{tabular}{|l|l|}
\hline Distribution in years & No/total no (\%) \\
\hline $0-14$ & $1 / 66(1.51 \%)$ \\
\hline $15-49$ & $46 / 66(69.69 \%)$ \\
\hline $50-64$ & $16 / 66(24.24 \%)$ \\
\hline$\geq 65$ & $3 / 66(4.54 \%)$ \\
\hline
\end{tabular}


Table 4 Presenting symptoms of COVID 19 positive cases

\begin{tabular}{|l|l|}
\hline Symptoms & No./ Total (\%) \\
\hline Fever on admission & $35 / 66(53.03 \%)$ \\
\hline Dry Cough & $21 / 66(31.81 \%)$ \\
\hline Shortness of breath & $19 / 66(28.78 \%)$ \\
\hline Myalgia / Fatigue & $7 / 66(10.60)$ \\
\hline Sore throat & $3 / 66(4.54 \%)$ \\
\hline Throat Pain & $3 / 66(4.54 \%)$ \\
\hline Dyspnoea & $2 / 66(3.03 \%)$ \\
\hline Vomiting & $1 / 66(1.5 \%)$ \\
\hline A new loss of taste sensation & $1 / 66(1.5 \%)$ \\
\hline Diarhoea & $1 / 66(1.51 \%)$ \\
\hline Hemoptysis & $2 / 66(3.03 \%)$ \\
\hline Headache & $2 / 66(3.03 \%)$ \\
\hline $\begin{array}{l}\text { Asymptomatic } \\
\text { no / total no }\end{array}$ & $15 / 66(22.72 \%)$ \\
\hline
\end{tabular}

Table 5 Number of COVID 19 positive cases with comorbidity

\begin{tabular}{|l|l|}
\hline Co-existing disorder & No/Total (\%) \\
\hline Chronic Obstructive pulmonary disease & $2 / 66(3.03 \%)$ \\
\hline Diabetes & $5 / 66(7.57 \%)$ \\
\hline Hypertension & $3 / 66(4.54 \%)$ \\
\hline Cardiovascular disease & $4 / 66(6.06 \%)$ \\
\hline Chronic Liver Disease & $1 / 66(1.51 \%)$ \\
\hline Malignancy & $1 / 66(1.51 \%)$ \\
\hline Chronic Renal disease & $1 / 66(1.51 \%)$ \\
\hline Immunodeficiency (HIV) & $1 / 66(1.51 \%)$ \\
\hline Pulmonary Tuberculosis & $2 / 66(3.03 \%)$ \\
\hline Post Renal Transplant & $1 / 66(1.51 \%)$ \\
\hline No of patients with comorbidity & $15 / 66(22.72 \%)$ \\
\hline No of patients without any comorbidity & $51 / 66(77.27 \%)$ \\
\hline
\end{tabular}




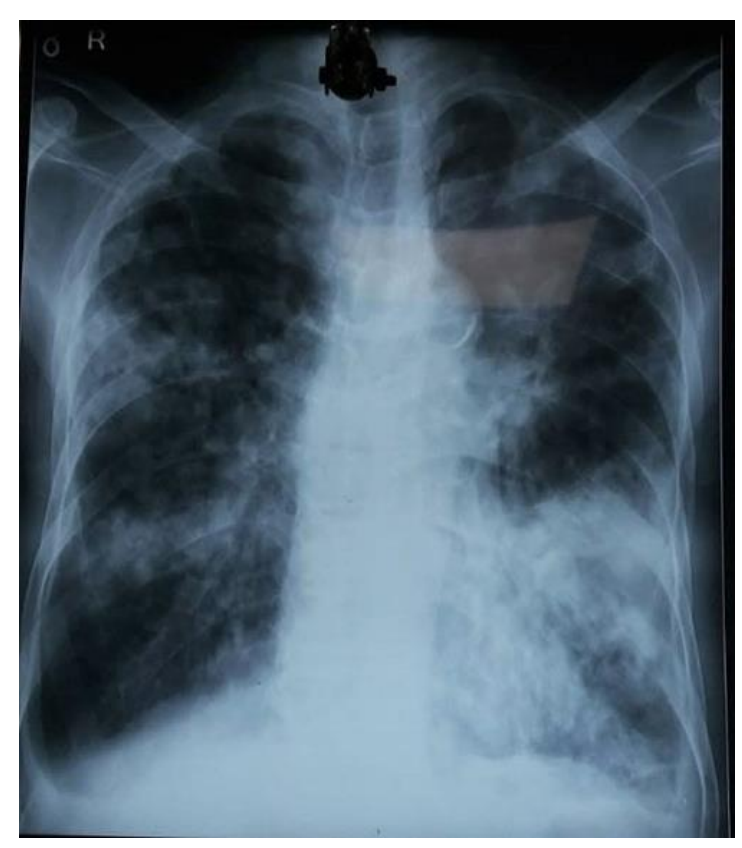

Figure 1 Chest X Ray of a COVID 19 patient

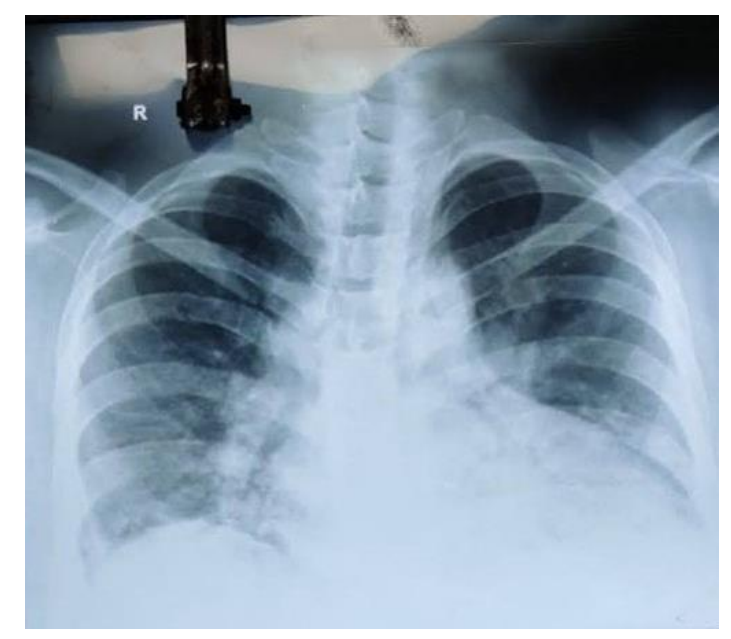

Figure 2 Chest X Ray Of a pregnant COVID 19 patient

Out of total 178 suspected cases of COVID 19, confirmed positive case were 66 in number between April 1, 2020 to June 12 , 2020. Among these males were $44(66.66 \%)$ and females were $22(33.33 \%)$. The median age of the patients was 37 years. Inter Quartile Range was 30-51. (Table 1)

Among 66 COVID 19 positive patients 11 were Health Care Workers.

Only 10 patients (15.15\%) had history of contact with COVID 19 positive patients. No patient had any positive travel history to China or abroad in last 14 days. (Table 2)

Most of the confirmed COVID 19 patients, who reported to our hospital, were young and middle aged. Patients between 15 to 49 years of age were 46 in number (69.69\%). Only one patient was aged between 0 to 14 years (1.51\%). Patients aged between 50 to 64 years were $16(24.24 \%)$ and patient aged 65 or more were 3 (4.54\%). (Table 3)

Asymptomatic patients were 15 in number $(22.72 \%)$. Fever was the most common presenting symptom with 35 patients presenting with fever (53.03\%). (Table 4)

Diabetes was the most common comorbidity associated with COVID 19 infection. Five COVID 19 positive patients were known diabetics (7.57\%). (Table 5) 
Asymptomatic and mild symptomatic patients were kept in isolation at Covid Care Centre (CCC) for 17 days from date of sampling and were advised for 7 days home isolation after discharge from CCC.

Moderate and severely ill patients were 17 in number (25.75\%), out of which 3 (4.54\%) died. In severe patients ground glass opacity was the most common finding in chest X-Ray. In most of the patient's Neutrophils were raised and Lymphopenia was seen. Out of the three patients who expired, two of them had no known comorbidity, but they belonged to low socioeconomic status and were undernourished. Both of them were admitted in ICU and underwent invasive mechanical ventilation. One of them had pulmonary Tuberculosis 20 years back.

Out of total 425 deliveries in hospital in this duration, only two females who were in labour turned out to be COVID 19 positive. One of them was from containment zone.

Figure 1 is the chest X-Ray of patient who died of infection with COVID 19 after one week of treatment. Figure 2 is the chest X-Ray of a pregnant patient who recovered within 2 weeks of the onset of symptoms.

We divided our patients in two groups according to timeline of COVID 19 in India. First group comprised of patients who came in lockdown period, i.e. till 31st May 2020 and second group of those patients who reported after 31st May 2020, when the lockdown was relaxed. We observed that out of 63 suspected patients who came in lockdown period, only 23 were COVID 19 positive (36.50\%) and number of deaths was only one (4.34\%). After lockdown was lifted, then in only 12 days number of reported suspect patients increased to 85, out of which COVID 19 positive patients were 43 $(50.58 \%)$ and deaths were $2(4.65 \%)$.

The 2019- SARS nCoV is highly contagious and infectious virus.[8] The scientists haven't seen SARS- CoV-2 before.[9] The failure to be alert and international air travel has spread this virus throughout world and caused pandemic. It has affected health, economy and social life of the whole world.[10] To prevent spread of this virus many countries are using containment and mitigation activities to prevent medical surge and protect major vulnerable groups from infection i.e. children, elderly and those with comorbidity.[11] In India lockdown was implemented from 25th March 2020 to 31st May 2020 in different phases.[12] In our study we observed that out of 63 suspected patients who came in lockdown period 23 were COVID 19 positive (36.50\%) and number of deaths was $1(4.34 \%)$. After lockdown was lifted then in only 12 days no of patients increased to 85, out of which COVID 19 positive patients were $43(50.58 \%)$ and deaths were $2(4.65 \%)$.

So, we can clearly see that lockdown was effective in controlling rate of infection which spiralled after relaxation of lockdown.

The median age of the patients was 37 years with range of 13 to 71 years. IQR was 30 - 51. However, Wei-jei Guan et al.[13] have reported median age 47 and IQR 35 to 58 years in study done in China Similarly, in a study done in Wuhan, China the median age of patients was 49 years (IQR $41-58$ ).[14] In an article published by Diwanji S, in India the age group between 31 and 40 years old were the most affected.[15]

COVID 19 infected males were more than females in our study. Among all patients 63.63\% were males and 33.33\% were females. Prof Chaolin et al. have also reported 73\% males in their study done in Wuhan China.[14] COVID 19 has affected young male population in India.[16] COVID 19 has affected working age group who go out for day to day work and get exposed to different people. Children and old people were less affected as they were mostly staying at home.

Our 10 patients i.e. $15.15 \%$ had contact history with positive COVID 19 patients. None of them had recent travel history to Wuhan or abroad. However, in a study done in India, 62\% of COVID 19 patients had travel history outside India.[16] Since lockdown was implemented in our country in the month of March 2020, and the first case of coronavirus disease was identified in our hospital in the month of April 2020, we didn't get any recent travel history outside India. Also an ICMR study has shown that 93\% of SARI patients who tested positive for COVID19 had neither contact history with COVID 19 positive patients nor had any abroad travel history [17].

The most common symptom at presentation was fever (53.03\%), followed by cough (31.81\%) and shortness of breath $(28.78 \%$ ) followed by body ache $10.60 \%$, sore throat $4.54 \%$, throat pain $4.54 \%$, chest pain $3.03 \%$, headache $3.03 \%$, haemoptysis $3.03 \%$, and diarrhoea in $1.51 \%$. These findings are in contrast to Prof Chaolin et al study, who found fever in $98 \%$ patients, cough in $76 \%$ patients, myalgia in $44 \%$ of patients, haemoptysis in $5 \%$, and diarrhoea in $3 \%$ of patients.[14] In a study published in Doc Wire News, it was found that the most common symptoms were fever cough and fatigue.[18] In a study done in India by Gupta $\mathrm{N}$ et al. the most common symptoms were fever and cough ( $42.2 \%)$, followed by sore throat headache and breathlessness.[16] Our 47\% patients were afebrile There are more afebrile 
patients in SARS-CoV-2 infection than SARS-CoV (1\%) and MERS-CoV infection (2\%).[19] Our 15 patients (22.72\%) were asymptomatic. The journal Annals of Internal Medicine has published findings after studying various countries that approximately 40 to $45 \%$ of SARS- CoV-2 infections may be asymptomatic.[20] Asymptomatic infection indicates that the virus is silently spreading into human populations. So, the detection of asymptomatic infection is a challenge in combating COVID 19 infection.

Two of our COVID 19 positive patients were pregnant and delivered babies. One of the mothers was asymptomatic COVID 19 positive and the other was moderately sick. The babies delivered were given bath soon after birth to remove virus from the body surface. The babies born to the confirmed COVID 19 positive cases were kept at six feet distance from their mother in our isolation ward. A mask was worn by the mother and breast and hand hygiene was performed for breast feeding. The asymptomatic mother was sent for home isolation with proper guidance. The other new born baby born to moderately sick mother was also tested for SARS-CoV-2. As the baby tested negative, baby was discharged and handed over to their non-infected care givers. The mother was finally discharged after 17 days from the date of sampling. Thereafter mothers and babies are doing well. One article published on the management of coexisting conditions in the context of COVID-19 advocate temporary separation of mother and baby to decrease incidence of postnatal infection and if possible then COVID 19 testing of the new born [21]. It also says that well babies born to COVID 19 positive mothers who do not require any medical intervention should remain with their mothers [21].

The most common coexisting disorders in our set-up were diabetes (7.57\%), cardiovascular disease (6.06\%) and hypertension (4.54\%). Among all SARS-CoV-2 infected patients 51(77.27\%) had no comorbidity while other 15 (22.72 $\%$ ) had one or more comorbidities. A nationwide analysis in China shows hypertension as most prevalent comorbidity (16.9\%) followed by diabetes (8.2\%).[22] Richardson $S$ and et al. have found hypertension as most common comorbidity $(56.6 \%)$, followed by obesity $(41.7 \%)$ and diabetes $(33.8 \%)$ in their study among hospitalized patients with COVID 19 in New York City Area.[23]

The case fatality rate in our study was $4.54 \%$, which was more than a study in China by Wei-jie Guan et al (1.4\%).[13] However case fatality rate was higher in some other studies [24,25]. In Tambe et al study, case fatality rate was $29.4 \%$. [26] The National average figure in India is $3.22 \%$ till 20 June 2020.

Figure 1. is the chest X Ray of patient who died due to infection with SARS-Cov-2 and Figure 2 is the chest X-Ray of patient who recovered in 2 weeks of the onset of symptoms. The figure shows bilateral ground glass opacity, lower lobe consolidation. The most common findings in X Ray of COVID 19 infected patients are air space opacity or consolidation, the lower zone of lung is predominantly involved. Parenchymal abnormality and pleural effusion are rare in COVID 19 infection.27

Out of 66 COVID 19 positive patients 11 (13.63\%) were our Health Care Workers (HCW). Since there is community transmission in New Delhi, HCW might have got infected in community or may be due to breach in PPE, also eating and drinking together might have caused spread among HCW.

\section{Conclusion}

Fever is the most common presenting symptom but fever should not be the exclusion criteria. Since there is silent spread of virus in the community among the asymptomatic patients there is need to increase the number of testing. Containment and mitigation strategy should be followed till treatment is available or vaccine is developed. Social distancing should be maintained to prevent secondary surge. Pregnant patients are at no greater risk of contracting COVID 19 infection than general population. Also, there is no evidence of vertical transmission from mother to babies. Routine screening of Health Care Workers should be done. There should be staggering of lunch hours in hospitals and offices to prevent spread of infection.

\section{Compliance with ethical standards}

\section{Acknowledgments}

Dr Lata Kamat, HOD, Department of Radiology, ESI Hospital, Okhla, New Delhi.

\section{Disclosure of conflict of interest}

None 


\section{Statement of ethical approval}

Informed consent was obtained from all individual participants included in the study.

\section{References}

[1] Darville JM. Coronaviruses. In: Greenwood D, Slack R, Peutherer J, Barer M. Medical microbiology: a guide to microbial infections: pathogenesis, immunity, laboratory diagnosis and control. 17th Edition. Edinburgh, Churchill Livingstone/Elsevier. 2012.

[2] Enjuanes L, Brian D, Cavanagh D, Holmes K, Lai MMC, Laude H, et al. Coronaviridae. In: van Regenmortel MHV, Fauquet CM, Bishop DHL, Carsten EB, Estes MK, Lemon SM, et al, editors. Virus Taxonomy, Classification and nomenclature of viruses. New York: Academic Press. 2000; 835-49.

[3] Myint SH. Human Coronavirus: A brief review. Rev Med Virol. 1994; 4: 35-46

[4] Kuiken T, Fouchier RAM, Schutten M, Rimmelzwaan GF, van Amerongen G, van Riel D, et al. Newly discovered coronavirus as the primary cause of severe acute respiratory syndrome. Lancet. 2003; 362: 263-70.

[5] Cennimo DJ, Bergman SJ, Olsen KM, Miller MM: Ed. Windle LM, Bronze MS; Coronavirus Disease 2019(Covid-19). e Medicine Medscape. Com. Jun 012020.

[6] Symptoms of Coronavirus. https://www.cdc.gov/coronavirus/2019-ncov/symptoms-testing/symptoms.html

[7] Davis K, Goodwin M. All you need to know about COVID-19. Medical News Today. May 20, 2020.

[8] Sanche S, Lin YT, Xu C, Romero- Severson E, Hengartner N, Ke R. The Novel Coronavirus 2019-nCoV is Highly Contagious and More Infectious Than Initially Estimated. Med Rxiv.

[9] Katella K. 5 Things Everyone Should Know About the Coronavirus Outbreak. Yale Medicine. June 22, 2020.

[10] Nicola M, Alsafi Z, Sohrabi C, Kerwan A, Al- Jabir A, Iosifidis C, et al. The socio-economic implications of the coronavirus pandemic (COVID-19): A review. Int J Surg. 2020; 78: 185-93.

[11] Bedford J, Enria D, Giesecke J, Heymann D L, Ihekweazu C, Kobinger G, Lane HC, et al. COVID-19: towards controlling of a pandemic. The Lancet. Elsevier. 28 March-3 April 2020.

[12] COVID-19 pandemic lockdown in India.

[13] Guan W, Ni Z, Hu Y, Liang W, Ou C, He J, et al. Clinical Characteristics of Coronavirus Disease 2019 in China. N Engl J Med. 2020; 382: 1708-20.

[14] Huang C, Wang Y, Li X, Ren L, Zhao J, MDet Y H et al. Clinical features of patients infected with 2019 novel coronavirus in Wuhan, China. The Lancet. Feb 15, 2020; 395(10223): 497-506.

[15] Diwanji S. Number of COVID-19 cases India 2020 by age group. Statista. Apr 29, 2020.

[16] Gupta N, Agarwal S, Ish P, Mishra S, Gaind R, Usha G, et al. Clinical and epidemiologic profile of the initial COVID19 patients at a tertiary care centre in India. Monaldi Arch Chest Dis.

[17] Nagaranjan R. Many COVID cases without travel or contact history- shows ICMR study.

[18] Wang Z, Yang B, Li Q, Wen L, Zhang R. Clinical Features of 69 Cases with Coronavirus Disease 2019 in Wuhan, China. Clin Infect Dis. 2020; ciaa272.

[19] Zumla A, Hui DS, Perlman S. Middle East respiratory syndrome. Lancet 2015; 386: 995-1007.

[20] Daniel P, Oran AM, Eric J, Topol MD. Prevalence of Asymptomatic SARS-CoV-2 Infection. Annals of Internal Medicine. 3 June 2020.

[21] Management of coexisting conditions in the context of COVID-19-Summary of relevant conditions. BMJ Best Practice. May 2020.

[22] Guan W, Liang W, Zhao Y, Liang H, Chen Z, Li Y et al. Comorbidity and its impact on 1590 patients with Covid-19 in China: A Nationwide Analysis. European Respiratory Journal. Jan 2020; 2000547.

[23] Richardson S, Hirsch JS, MD, Narasimhan M et al. Presenting Characteristics, Comorbidities, and Outcomes Among 5700 Patients Hospitalized With COVID-19 in the New York City Area. JAMA. 2020; 323(20): 2052-2059. 
[24] Chen N, Zhou M, Dong X, Qu J, Gong F, Han Y, et al. Epidemiological and clinical characteristics of 99 cases of 2019 novel coronavirus pneumonia in Wuhan, China: a descriptive study. Lancet. 2020; 395: 507-13.

[25] Wang D, Hu B, Hu C, Zhu F, Liu X, Zhang J, et al. Clinical Characteristics of 138 Hospitalized Patients With 2019 Novel Coronavirus-Infected Pneumonia in Wuhan, China. JAMA. 2020; 323(11): 1061-69.

[26] Tambe MP, Parande MA, Tapare VS, Borle PS, Lakde RN, Shelke SC. An epidemiological study of laboratory confirmed COVID-19 cases admitted in a tertiary care hospital of Pune, Maharashtra. IJPH. 2020; 64, 6: 183-7.

[27] Bell DJ et al. COVID-19. https://radiopaedia.org/articles/covid-19-4?lang=us 